\title{
Evaluation of the inhibitory effect of tacrolimus combined with mycophenolate mofetil on mesangial cell proliferation based on the cell cycle
}

\author{
YANFANG GAO $^{1}$, HUI YANG ${ }^{1}$, YANHONG WANG ${ }^{2}$, JIHUA TIAN $^{2}$, RONGSHAN LI $^{1}$ and XIAOSHUANG ZHOU ${ }^{1}$ \\ ${ }^{1}$ Department of Nephrology, The Affiliated People's Hospital of Shanxi Medical University, \\ Shanxi Provincial People's Hospital, Shanxi Kidney Disease Institute; ${ }^{2}$ Department of Microbiology and Immunology, \\ Shanxi Medical University, Taiyuan, Shanxi 030001, P.R. China
}

Received February 12, 2020; Accepted July 13, 2020

DOI: $10.3892 /$ ijmm.2020.4696

\begin{abstract}
The inhibition of mesangial cell proliferation has become an important therapy for the prevention of glomerular proliferation-associated diseases. The combined application of immunosuppressants with multiple targets presents a novel direction in the treatment of kidney diseases. The present study was designed to explore the inhibitory effects of tacrolimus (TAC) combined with mycophenolate mofetil (MMF) on the proliferation of mesangial cells based on the cell cycle. In vitro, the levels of the proliferation index markers, Ki67 and cyclin D1, in human mesangial cells (HMCs) were determined by immunofluorescence staining and western blot analysis, respectively. In mice with lupus nephritis (LN), the proliferation of mesangial cells was determined using PAS and Masson's trichrome staining, while immunohistochemistry was used to detect $\mathrm{Ki67}$ and western blot analysis was employed for the evaluation of cyclin D1 levels. The expression of platelet-derived growth factor (PDGF), a proliferation-associated protein, was estimated using immunohistochemistry and western blot analysis. In patients with LN, Ki67, cyclin D1 and PDGF expression was estimated by immunohistochemistry. The transforming growth factor- $\beta 1 /$ Smad pathway influenced by TAC and the p38 pathway influenced by MMF were also examined by western blot analysis. The results suggested that the combination of TAC and MMF at half the concentration based on the cell cycle was more effective than monotherapy in inhibiting mesangial cell proliferation in vitro and in vivo. TAC inhibited HMC proliferation by affecting the Smad2
\end{abstract}

Correspondence to: Dr Xiaoshuang Zhou, Department of Nephrology, The Affiliated People's Hospital of Shanxi Medical University, Shanxi Provincial People's Hospital, Shanxi Kidney Disease Institute, 29 Shuang Ta East Street, Taiyuan, Shanxi 030001, P.R. China

E-mail: xiaoshuangzhou66@163.com

Key words: cell cycle, mesangial cells, immunosuppressive agents, multi-target therapy signaling pathway. MMF inhibited HMC proliferation by affecting the p38 signaling pathway. Combined treatment with TAC and MMF significantly improved the clinical indexes of patients with LN without severe adverse effects. On the whole, the findings of the present study validate and reinforce the potential use of the combination of TAC and MMF for the treatment of mesangial proliferative diseases.

\section{Introduction}

The abnormal proliferation of mesangial cells is a common pathological alteration in proliferative glomerular diseases, such as lupus nephritis (LN). The inflammatory reaction or cell injury triggers the abnormal proliferation of mesangial cells, and the activation and operation of the cell cycle, which ultimately leads to glomerulosclerosis and end-stage renal failure. The interference of the cell cycle at any stage can prevent cell proliferation or promote cell apoptosis (1). Hormones, immunosuppressants, immunomodulatory drugs and their combination therapies are commonly used to address mesangial cell proliferation induced by glomerulonephritis. However, these drugs have a narrow therapeutic window and severe side-effects $(2,3)$. Clinically, the chemotherapeutic treatment of leukemia involves a combination of various chemotherapeutic drugs, which are administered sequentially in a planned manner according to the cell cycle of leukemia cells. The leukemia cells are blocked at a certain stage of cell cycle proliferation, and subsequently non-specific drugs of the cell cycle are used to kill the viable leukemia cells, so that remission and intensive treatment can be achieved by repeating consolidation (4-6). The combination of multiple immunosuppressive agents and sequential therapy for renal transplant recipients and patients with myeloid leukemia has been successful (7). Liu et al (8), as well as others $(9,10)$ proposed the concept of multi-target therapy, and carried out large-scale, randomized, open, multi-center research, which achieved a good therapeutic effect. Therefore, it was speculated that a complementary or sequential immunosuppressive therapeutic strategy may be more effective in inhibiting the proliferation of human mesangial cells (HMCs). In a previous study by the authors, it was revealed that tacrolimus (TAC) and 
mycophenolate mofetil (MMF) exerted their inhibitory effect on mesangial cell proliferation by acting on different phases of the cell cycle of mesangial cells (11). Thus, TAC combined with $\mathrm{MMF}$ at half the concentration was selected in the present study for the treatment of the proliferative stage of mesangial cells in vitro and to explore the therapeutic effect in vivo. The present study provides a theoretical basis for the treatment of mesangial proliferative nephropathy by using multiple immunosuppressants according to the cell cycle.

\section{Materials and methods}

Animals. A total of 6 female C57BL/6 mice (8 weeks old; weighing $\sim 20 \pm 5 \mathrm{~g}$ ) were purchased from the Experimental Animal Center of Shanxi Medical University, while 24 female MRL/lpr mice ( 8 weeks old; weighing 27-31 g) were purchased from the Nanjing Model Animal Research Institute (originally from Jackson Laboratory). The animals were allowed to adapt to their surroundings and fed until the age of 3 months in an environment with constant temperature $\left(22 \pm 1^{\circ} \mathrm{C}\right)$, relative humidity $(65-70 \%)$ and a $12 \mathrm{~h}: 12 \mathrm{~h}$ light/dark cycle. The animals were provided with free access to water and were fed a standard laboratory diet. The experiments were performed according to protocols approved by the Institutional Animal Care and Use Committee of Shanxi Medical University.

Treatment protocols. A total of 6 C57BL/6 mice served as the control group. The MRL/lpr mice were randomly divided into 4 groups (n=6/group) as follows: The lupus group, the lupus $+\mathrm{T}$ group, the lupus $+\mathrm{M}$ group and the lupus $+1 / 2 \mathrm{~T}+1 / 2 \mathrm{M}$ group. The mice in the lupus $+\mathrm{T}$ group received an intraperitoneal injection of $1 \mathrm{mg} / \mathrm{kg} /$ day TAC (Sigma-Aldrich; Merck $\mathrm{KGaA}$ ). The mice in the lupus $+\mathrm{M}$ group received an intragastric administration of $60 \mathrm{mg} / \mathrm{kg} /$ day MMF (Sigma-Aldrich; Merck KGaA). The mice in the lupus $+1 / 2 \mathrm{~T}+1 / 2 \mathrm{M}$ group received an intraperitoneal injection of $0.5 \mathrm{mg} / \mathrm{kg} /$ day $\mathrm{TAC}+30 \mathrm{mg} / \mathrm{kg} /$ day MMF. The mice in the lupus $+\mathrm{T}$, lupus $+\mathrm{M}$ and lupus $+1 / 2 \mathrm{~T}+1 / 2 \mathrm{M}$ groups received the drugs from the age of 3 months. At the age of 6 months, the experiment was completed. The mice were anesthetized by an intraperitoneal injection of $2 \%$ pentobarbital sodium at a dose of $45 \mathrm{mg} / \mathrm{kg}$ body weight. Following saline lavage, both kidneys were immediately removed, and the renal cortex was extracted. Some samples were fixed in formaldehyde solution, and some were stored in a refrigerator at $-70^{\circ} \mathrm{C}$ for further analyses.

Cell culture and treatments. The HMC line, T-SV40 (12), used in the present study was kindly donated by Professor Xuewang Li of Peking Union Medical College Hospital. The HMCs were cultured in DMEM (Gibco; Thermo Fisher Scientific, Inc.) containing $10 \%$ fetal calf serum (Hangzhou Sijiqing Biological Engineering Materials Co., Ltd.) and placed in a $37^{\circ} \mathrm{C}, 5 \% \mathrm{CO}_{2}$ incubator. HMCs in logarithmic growth phase were fused up to $60 \%$. Following $24 \mathrm{~h}$ of culture in serum-free DMEM, the cells were randomly divided into the CTL group, the PDGF group, the PDGF + T group, the PDGF + M group, and the PDGF $+1 / 2 \mathrm{~T}+1 / 2 \mathrm{M}$ group. In the CTL group, the HMCs were cultured routinely; in the PDGF group, the HMCs were stimulated with $20 \mathrm{ng} / \mathrm{ml}$ platelet-derived growth factor (PDGF) for $48 \mathrm{~h}$; in the PDGF $+\mathrm{T}$ group, the HMCs were stimulated with $20 \mathrm{ng} / \mathrm{ml}$ PDGF and cultured for $24 \mathrm{~h}$, and the cells were then treated with $5 \mu \mathrm{mol} / 1 \mathrm{TAC}$ and further cultured for $24 \mathrm{~h}$. In the PDGF + M group, the HMCs were stimulated with $20 \mathrm{ng} / \mathrm{ml}$ PDGF and cultured for $24 \mathrm{~h}$, and were then treated with $10 \mu \mathrm{mol} / \mathrm{MMF}$ and further cultured for an additional $24 \mathrm{~h}$. In the PDGF $+1 / 2 \mathrm{~T}+1 / 2 \mathrm{M}$ group, the $\mathrm{HMCs}$ were stimulated with $20 \mathrm{ng} / \mathrm{ml}$ PDGF and cultured for $24 \mathrm{~h}$. The cells were then treated with $2.5 \mu \mathrm{mol} / 1 \mathrm{TAC}$ and $5 \mu \mathrm{mol} / 1$ $\mathrm{MMF}$, and further cultured for $24 \mathrm{~h}$. For these treatments, the culture conditions of the cells were the same as those above in a $37^{\circ} \mathrm{C}, 5 \% \mathrm{CO}_{2}$ incubator.

There were 2 grouping methods used in the present study. One grouping method comprised: Normal HMCs, HMCs treated with $5 \mathrm{ng} / \mathrm{ml}$ TGF- $\beta 1$, HMCs treated with $5 \mu \mathrm{mol} / 1$ TAC and HMCs treated with $5 \mathrm{ng} / \mathrm{ml}$ TGF- $\beta 1+5 \mu \mathrm{mol} / \mathrm{l}$ TAC for $48 \mathrm{~h}$. Another grouping method comprised: Normal HMCs, HMCs treated with $20 \mathrm{ng} / \mathrm{ml}$ PDGF, HMCs treated with $10 \mu \mathrm{mol} / \mathrm{l} \mathrm{MMF}$ and HMCs treated with $20 \mathrm{ng} / \mathrm{ml}$ $\mathrm{PDGF}+10 \mu \mathrm{mol} / 1 \mathrm{MMF}$ for $48 \mathrm{~h}$ in a $37^{\circ} \mathrm{C}, 5 \% \mathrm{CO}_{2}$ incubator.

Patients and treatment. A total of 6 patients with LN were enrolled from the Shanxi Provincial People's Hospital between January and February, 2019. The inclusion criteria were as follows: i) Patients were of either sex, and between 15 and 65 years of age; ii) patients fulfilled the 1997 revised criteria for the classification of SLE (13); iii) patients had a diagnosis of class IV LN; and iv) patients had proteinuria levels $\geq 1.5 \mathrm{~g} / 24 \mathrm{~h}$ and serum creatinine levels $<265 \mu \mathrm{mol} / 1$, SLEDAI $\geq 12$. The key exclusion criteria were the following: i) The use of any immunosuppressant drug prior to entering the study; ii) severe infection; iii) central nervous system symptoms; iv) abnormal index of liver function; v) type 1 or 2 diabetes; vi) allergies to TAC or MMF; and vii) family planning, pregnancy and lactation during the previous 6 months. The Ethics Committee of Shanxi Provincial People's Hospital (Taiyuan, China) approved the study. Written informed consent was obtained from each patient or their legal representative, according to the Declaration of Helsinki.

Patients who entered the study received combined treatment with TAC ( $2 \mathrm{mg}$, twice daily), MMF (500 mg, twice daily) and methyl prednisone for 6 months and were followed-up. At the end of the 6-month follow-up period, the patients received a renal biopsy. The expression of cyclin D1, Ki67 and PDGF in the renal tissues was evaluated by immunohistochemistry. Changes in the SLEDAI score, 24-h proteinuria levels, the levels of estimated glomerular filtration rate (eGFR), serum albumin levels, anti-dsDNA antibodies, complement 3 (C3) and other clinical indicators were compared before and after treatment.

Immunofluorescence. The HMCs were washed with PBS for $10 \mathrm{~min}$ and fixed with $4 \%$ paraformaldehyde for $20 \mathrm{~min}$ after drying, washed with PBS containing 0.1\% Triton for $10 \mathrm{~min}$, sealed with Block solution (11921673001, Sigma-Aldrich; Merck KGaA) for $30 \mathrm{~min}$, incubated with a rabbit anti-Ki67 primary antibody (1:200 diluted with block solution; NCL-Ki67p, Novocastra Laboratories, British) at $4^{\circ} \mathrm{C}$ overnight, washed with PBS without Triton 3 times for $5 \mathrm{~min}$ each, incubated with Alexa Fluor conjugated goat anti-rabbit secondary antibody (A32731, Invitrogen; Thermo Fisher 
Scientific, Inc.) in the dark for $1 \mathrm{~h}$, washed with PBS 3 times (5 min each), and immediately observed under a fluorescence microscope (DM2500, Leica Microsystems GmbH).

Immunohistochemistry. Paraffin-embedded sections of the kidney tissues of the mice and biopsy samples of the patients were deparaffinized with xylene and rehydrated with ethanol. Endogenous peroxidase was removed by $3 \%$ hydrogen peroxide, followed by washing and placing the tissues in antigen repair solution. The tissues were repaired in a microwave oven for $2 \mathrm{~min}$, cooled down naturally to room temperature and cleaned 3 times. After blocking in Block solution (11921673001, Sigma-Aldrich; Merck $\mathrm{KGaA}$ ) for $30 \mathrm{~min}$, the mice samples were incubated with primary antibodies against Ki67 (NCL-Ki67p, Novocastra Laboratories) and PDGF (ab23914; Abcam). The patient samples were incubated with the human primary antibodies against Ki67 (NCL-Ki67p, Novocastra Laboratories), PDGF (AF220; R\&D Systems, Inc.) and cyclin D1 (MAB4314; R\&D Systems, Inc.) (1:200 diluted with block solution) at $4^{\circ} \mathrm{C}$ overnight. Following 3 rinses with PBS, secondary antibodies (PV-9000 or PV-9003; ZSGB-BIO Technology, Co., Ltd.) were added, and incubated at room temperature for 30 min. Following incubation with $\mathrm{AB}$ enzyme at room temperature for $30 \mathrm{~min}$, the samples were colored with $\mathrm{DAB}$, re-stained in hematoxylin, dehydrated, made transparent and observed after sealing. Immunohistochemical analysis was performed in a blinded manner by two independent investigators. Mice glomeruli were examined in a blinded manner using a high-power light microscope (DM2500, Leica Microsystems $\mathrm{GmbH}$ ) (magnification, x400). The Image-Pro Plus image analysis system was used to count the number of positive cells and total glomerular cells. Relative density was calculated as the ratio of positive cells to the total glomerular cells. The results were scored as follows: of,$+ 1-25 \%$ positive cells;,$++ 26-50 \%$ positive cells;,$+++ 51-75 \%$ positive cells; and,$++++ 76-100 \%$ positive cells.

PAS and Masson's trichrome staining. Paraffin blocks of resected tissues from these mice were cut into $5-\mu \mathrm{M}$-thick tissue sections and stained with the hematoxylin and eosin staining kit (cat. no. C0105; Beyotime Institute of Biotechnology, Inc.) and Masson's trichrome staining (Masson's Trichrome Stain kit, cat. no. TR-1303; ZSGB-Bio Co., Ltd.), respectively, according to the manufacturer's instructions. The stained tissue sections were then observed under a microscope (DM2500, Leica Microsystems GmbH).

Western blot analysis. The HMCs were washed twice with PBS. After drying, $250 \mu \mathrm{l}$ cell lysate (Sigma-Aldrich; Merck $\mathrm{KGaA}$ ) was added to each pore. Cells in the pore were gently scraped up and lysed on ice for $30 \mathrm{~min}$. The lysed cells were placed into an EP tube and centrifuged for $20 \mathrm{~min}$ at $4^{\circ} \mathrm{C}$ and $12,000 \mathrm{x} \mathrm{g}$. The supernatant was separated, and the protein concentration was measured by the BCA method. Proteins were denatured by mixing the sample with an equal volume of $2 \mathrm{X}$ loading buffer and boiling at $100^{\circ} \mathrm{C}$ for $5 \mathrm{~min}$, and were then cooled down to room temperature. A $15 \%$ prefabricated glue (Bio-Rad Laboratories, Inc.) with a higher concentration was selected, and the channel of the prefabricated glue was rinsed with Running Buffer (Beyotime Institute of Biotechnology) to ensure that the sample size of each lane protein was $50 \mu \mathrm{g}$. Electrophoresis was conducted at a constant voltage of $120 \mathrm{~V}, 100 \mathrm{~V}$ transmembrane for $1 \mathrm{~h}$ and $30 \mathrm{~min}$. After blocking with Block solution (11921673001, Sigma-Aldrich; Merck KGaA) for $30 \mathrm{~min}$, the following primary antibodies were added and incubated overnight at $4^{\circ} \mathrm{C}$ : Anti- $\beta$-actin (ZRB1312, Sigma-Aldrich; Merck KGaA), anti-cyclin D1 (ab16663, Abcam), anti-Smad2 (700048, Invitrogen; Thermo Fisher Scientific, Inc.), anti-phosphorylated (p)-p38 (sc-7973, Santa Cruz Biotechnology, Inc.) and anti-p38 (sc-7972, Santa Cruz Biotechnology, Inc.) (antibodies diluted 1:200 with block solution). After washing with TBST solution, horseradish peroxidase-conjugated secondary antibody $(1: 2,000)$ goat anti-rabbit IgG (ZB-5301, ZSGB-BIO Technology, Co., Ltd.) or goat anti-mouse IgG (ZB-5305, ZSGB-BIO Technology, Co., Ltd.) was added for hybridization, and incubated at room temperature for $1 \mathrm{~h}$. The membrane was then washed with TBST solution for $10 \mathrm{~min}$ (3 times in total). The absorbance of the results was analyzed using the Quantity One analysis system, version 4.62 version (Bio-Rad Laboratories, Inc.).

The mouse kidneys were cut and incubated with 3 -fold volume of cold lysis buffer (Beyotime Institute of Biotechnology). Subsequently, $10 \mu 1$ phosphatase inhibitors, $1 \mu 1$ protease inhibitors and $10 \mu \mathrm{l}$ PMSF $(1 \mathrm{mmol} / \mathrm{l})$ were added per $1 \mathrm{ml}$ lysis buffer. Upon incubation on ice for $15 \mathrm{~min}$, the tissues were fully grinded with a glass homogenizer, and centrifuged for $30 \mathrm{~min}$ at $4^{\circ} \mathrm{C}$ and $12,000 \mathrm{xg}$. The supernatant was then placed in another EP tube. The subsequent experimental steps were the same as described above. The following primary antibodies were applied: Anti- $\beta$-actin (ZRB1312, Sigma-Aldrich; Merck KGaA), anti-cyclin D1 (ab16663, Abcam), anti-PDGF (ab23914; Abcam). The secondary antibody used was horseradish peroxidase-conjugated goat anti-rabbit antibody (ZB-5301).

MTT assay. Cell proliferation was assessed using a MTT Cell Proliferation and Cytotoxicity Assay kit (Beijing Solarbio Science \& Technology Co., Ltd.) in accordance with the manufacturer's protocols. HMCs were grown in 96-well plates at a density of 5,000-10,000 cells/well and placed in a $37^{\circ} \mathrm{C}, 5 \% \mathrm{CO}_{2}$ incubator for $12 \mathrm{~h}$. Following $24 \mathrm{~h}$ of culture in serum-free DMEM and the following treatment, the supernatant was removed, and $90 \mu 1$ fresh culture medium were added. This was followed by the addition of $10 \mu \mathrm{l}$ MTT solution and further culture for $4 \mathrm{~h}$ in $37^{\circ} \mathrm{C}$. The cell supernatant was then discarded, and $110 \mu 1$ formazan were administered with gentle shaking for $10 \mathrm{~min}$. The absorbance was recorded at $490 \mathrm{~nm}$ with a Microplate Spectrophotometer (C-5000, Institute of Biophysics, Chinese Academy of Sciences).

Statistical analysis. Statistical analysis was performed using SPSS 21.0 software (IBM Corp). All experiments were repeated 3 times. The results were expressed as the means \pm standard deviation. One-way ANOVA followed by Tukey's test was used to detect differences between groups. $\mathrm{P}<0.05$ was considered to indicate a statistically significant difference. 


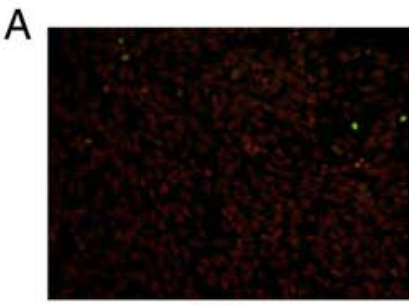

CTL

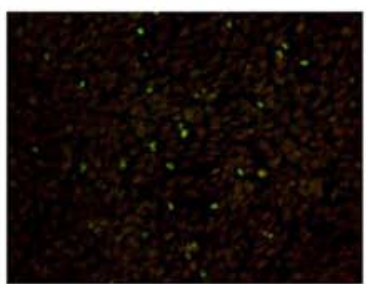

$\mathrm{PDGF}+\mathrm{T}$

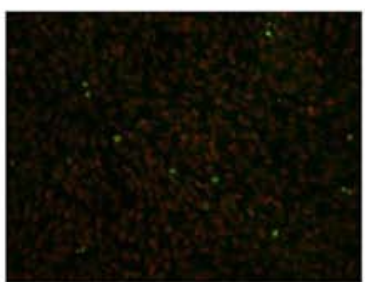

$\mathrm{PDGF}+1 / 2 \mathrm{~T}+1 / 2 \mathrm{M}$

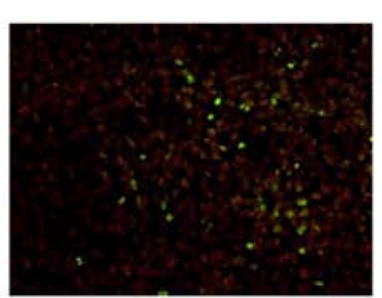

PDGF

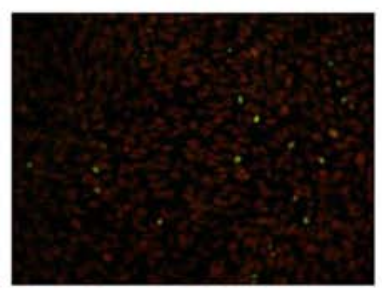

PDGF $+M$
B

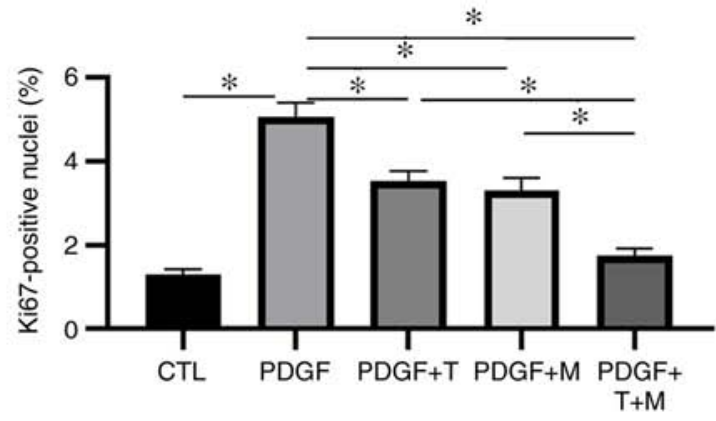

C

CTL
$\mathrm{PDGF}+\mathrm{T} \quad \mathrm{PDGF}+\mathrm{T} \quad \mathrm{PDGF}+\mathrm{T}+\mathrm{M}$

Cyclin D1

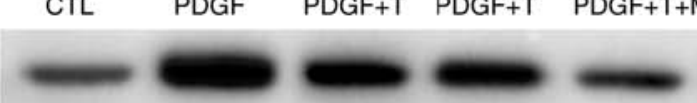

$\beta$-actin

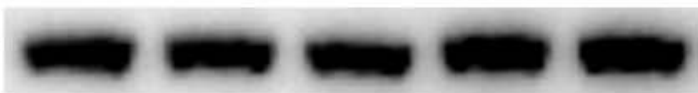

D

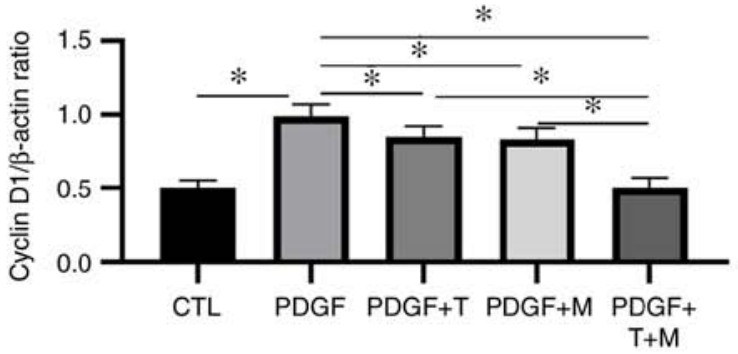

Figure 1. Combination of TAC and MMF at half the concentration exerts a more prominent inhibitory effect on HMC proliferation. (A) Ki67 immunohistochemistry (magnification, x100). (B) Ratio of Ki67-positive nuclei in HMCs. (C and D) Protein expression levels of cyclin D1, as examined by western blot analysis ( $\left.{ }^{*} \mathrm{P}<0.01\right)$. T or TAC, tacrolimus; $\mathrm{M}$ or MMF, mycophenolate mofetil; HMC, human mesangial cell.

\section{Results}

Combination of TAC and MMF at half the concentration exerts a more prominent inhibitory effect on HMC proliferation. $\mathrm{Ki} 67$ is present in all the active phases of the cell cycle, but is absent in resting cells (G0) (14). Its expression indicates the entry of the cell into the cell cycle. Therefore, $\mathrm{Ki} 67$ is a widely used marker of cell proliferation. Cyclin D1 represents the proliferation of mesangial cells, since it is a key protein that regulated the cell cycle and is significantly upregulated in the proliferative stage of mesangial cells (15). Thus, in the present study, these 2 markers were used to evaluate mesangial cell proliferation.

To investigate whether the combination of TAC and MMF at half the concentration exerted a more prominent inhibitory effect on HMC proliferation in vitro than the use of a single drug, the HMCs were divided into 5 groups as follows: CTL, PDGF, PDGF $+5 \mu \mathrm{mol} / 1 \mathrm{~T}, \mathrm{PDGF}+10 \mu \mathrm{mol} / 1 \mathrm{M}$ and $\mathrm{PDGF}+2.5 \mu \mathrm{mol} / 1$ plus $\mathrm{TAC}+5 \mu \mathrm{mol} / 1 \mathrm{MMF}$. The ratio of Ki67-positive nuclei and the expression of cyclin D1 in each group were measured by fluorescence staining and western blot analysis, respectively. The results revealed that the ratio of Ki67-positive nuclei and the expression of cyclin D1 in the PDGF group were significantly higher than those in the CTL group. Following treatment with TAC, MMF or $1 / 2 \mathrm{TAC}+1 / 2 \mathrm{MMF}$, the ratio of Ki67-positive nuclei and the expression of cyclin D1 were significantly decreased. These changes indicated that all 3 treatment regimens inhibited mesangial cell proliferation. Furthermore, the ratio of Ki67-positive nuclei and the expression of cyclin D1 were lower following treatment with $1 / 2 \mathrm{TAC}+1 / 2 \mathrm{MMF}$ compared with following treatment with either TAC or MMF alone, and the difference was statistically significant, indicating that the combination of TAC and MMF was more effective than monotherapy in vitro (Fig. 1).

Combination of TAC and MMF at half the concentration exerts a more prominent inhibitory effect on mesangial cell proliferation in mice with LN than using a single drug. Spontaneous lupus MRL/lpr mice are one of the recognized pathological models for the study of mesangial proliferative nephropathy (16). At the age of 3-6 months, the disease in these mice manifests as a simple hyperplasia of mesangial cells. The present study commenced when the mice were 3 months old and was completed when the animals had an age of 6 months. The proliferation of mesangial cells in the kidneys of the mice with lupus treated with the various regimens (TAC, MMF and $1 / 2 \mathrm{TAC}+1 / 2 \mathrm{MMF}$ ) was observed.

PAS staining and Masson's trichrome staining revealed that, at the end of the experiment, the renal tissue structure of the wild-type mice was normal under a light microscope, while the lupus group exhibited evident pathological changes, 
A

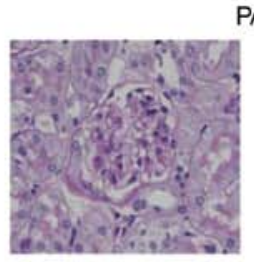

wt (+)
PAS

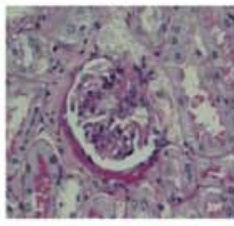

Lupus (+++++)

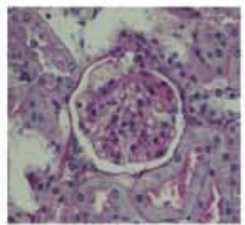

Lupus $+\mathrm{T}(++++)$

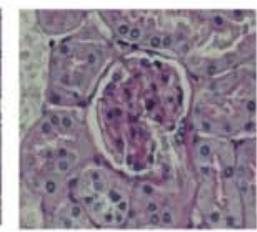

Lupus+M (++++)

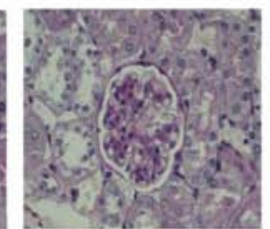

Lupus $+\mathrm{T}+\mathrm{M}(++)$
C

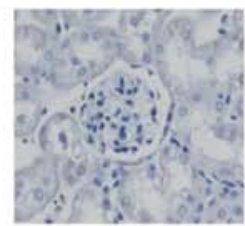

wt (+)

Ki67

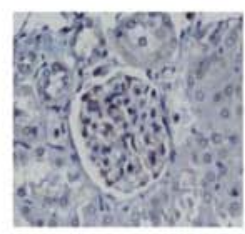

Lupus $(+++++)$

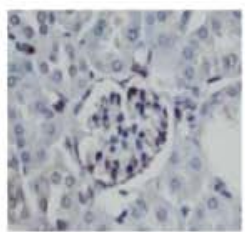

Lupus+T (++++)

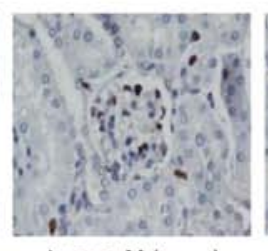

Lupus+M (++++)

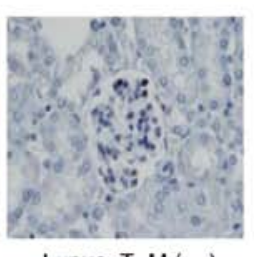

Lupus+T+M (++)

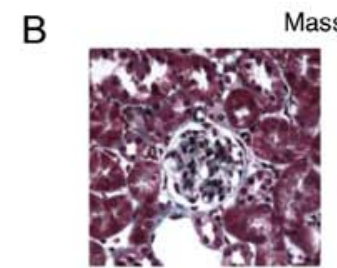

wt (+)
Masson's

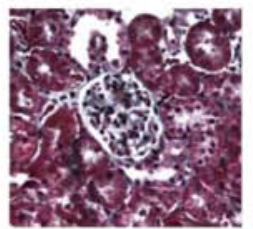

Lupus+T (++++)

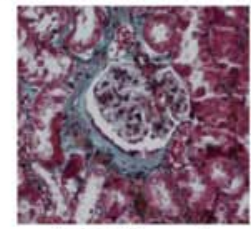

Lupus (+++++)

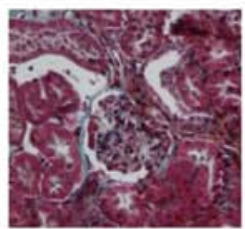

Lupus+M (++++)

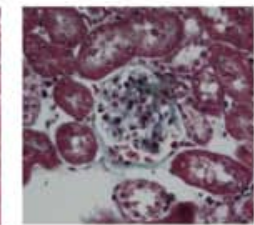

Lupus $+\mathrm{T}+\mathrm{M}(++)$

D

PDGF
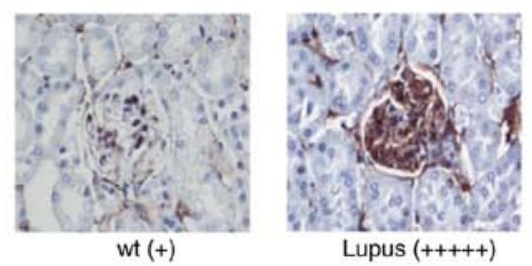

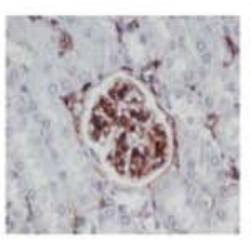

Lupus+T (++++)

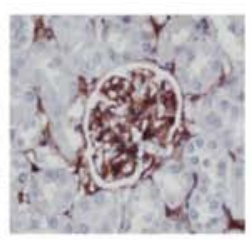

Lupus+M (++++)

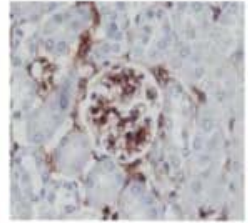

Lupus $+\mathrm{T}+\mathrm{M}(++)$

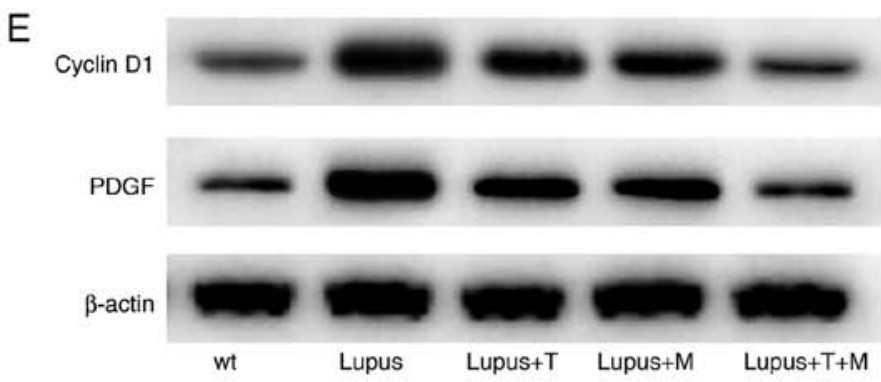

$\mathrm{F}$

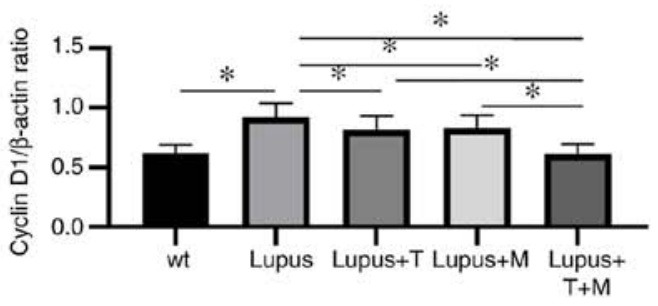

$\mathrm{G}$

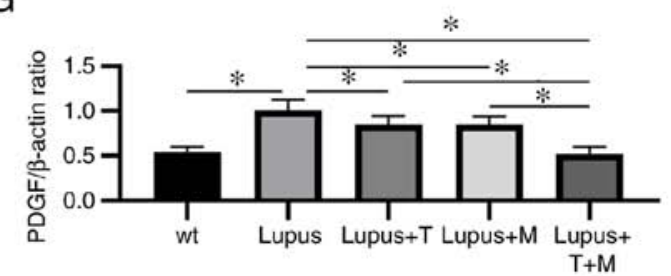

Figure 2. Combination of TAC and MMF at half the concentration exerts a more prominent inhibitory on mesangial cell proliferation in mice with lupus nephritis than using a single drug. (A and B) PAS and Masson's trichrome staining (magnification, x400). (C and D) Ki67 and PDGF immunohistochemistry (magnification, $x 400)$. (E-G) The protein expression levels of PDGF and cyclin D1 were examined by western blot analysis ( $\left.{ }^{*}<<0.01\right)$. PAS, Periodic acid-Schiff stain; T or TAC, tacrolimus; M or MMF, mycophenolate mofetil.

namely the proliferation of mesangial cells, the destruction of glomerular structure and a large number of infiltrated inflammatory cells. The pathological changes in the lupus $+\mathrm{T}$ and lupus $+\mathrm{M}$ groups were less than those in the lupus group: The mesangial cells proliferated less, glomerular structure destruction was not as evident, and inflammatory cell infiltration was lower. Compared with those in the lupus $+\mathrm{T}$ and the lupus $+M$ groups, the pathological changes in the lupus $+1 / 2 \mathrm{~T}+1 / 2 \mathrm{M}$ group were markedly attenuated, the mesangial cells proliferated less, the glomerular structure was not markedly damaged, and the number of infiltrated inflammatory cells was lower (Fig. 2A and B).

According to the results of immunohistochemistry, the expression of Ki67 and PDGF in the lupus group was 
A

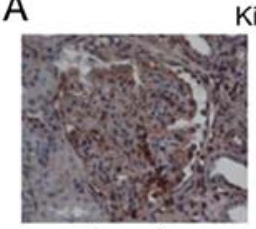

$(++++)$

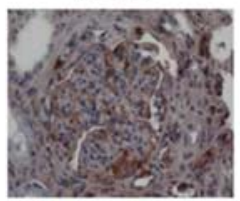

$(++++)$

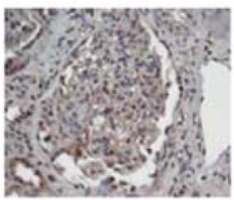

$(+++)$

Before
Ki67

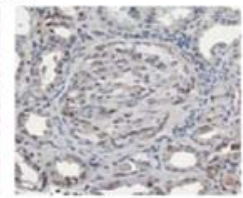

$(++)$

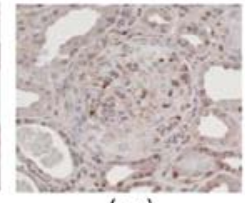

$(++)$

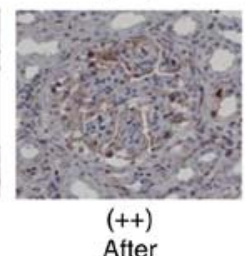

B

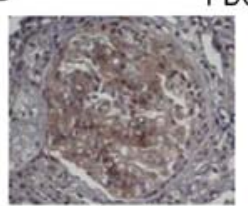

$(++++)$

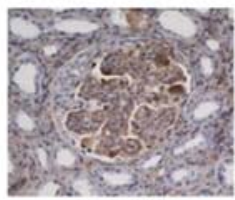

$(+++++)$

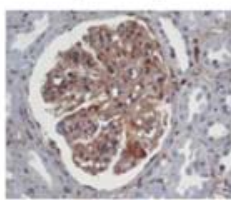

$(+++++)$

Before
PDGF

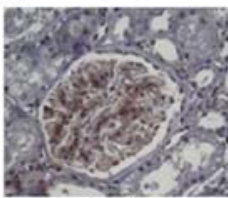

$(++)$

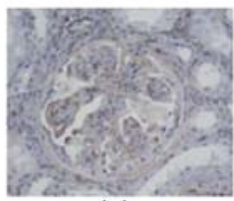

$(+)$

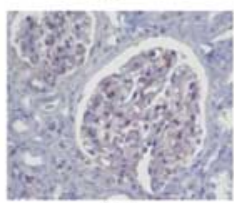

(+)

After
C

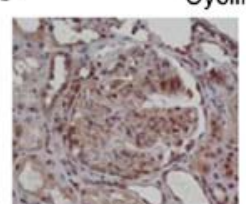

$(++)$

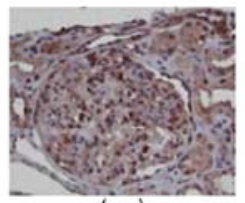

$(++)$

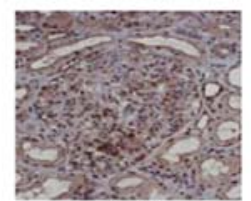

(++)

Before
Cyclin D1

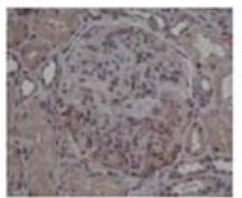

(+)

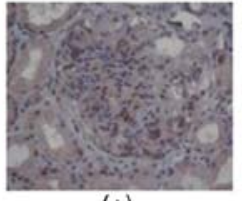

$(+)$

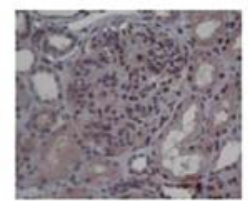

(+)

Figure 3.Combination of tacrolimus and mycophenolate mofetil inhibits the proliferation of mesangial cells in patients with lupus nephritis. Immunohistochemical staining images and semi-quantitative analysis of the results are shown: (A) Ki67 immunohistochemistry (magnification, x400), (B) PDGF immunohistochemistry (magnification, $\mathrm{x} 400$ ) and (C) cyclin D1 immunohistochemistry (magnification, $\mathrm{x} 400$ ) before and after 6 months of treatment.

significantly higher than that in the wild-type group. The expression levels of Ki67 and PDGF in the lupus + T, lupus + M and lupus $+1 / 2 \mathrm{~T}+1 / 2 \mathrm{M}$ groups were markedly decreased compared with those in the lupus group. Compared with that in the lupus $+\mathrm{T}$ and lupus $+\mathrm{M}$ groups, the expression of Ki67 and PDGF decreased markedly in the lupus $+1 / 2 \mathrm{~T}+1 / 2 \mathrm{M}$ group (Fig. 2C and D).

The results of western blot analysis indicated that the expression of cyclin D1 and PDGF decreased following treatment with TAC, MMF and $1 / 2 \mathrm{~T}+1 / 2 \mathrm{M}$. Compared with that following treatment with TAC and MMF alone, the expression of cyclin D1 and PDGF significantly decreased following treatment with $1 / 2 \mathrm{~T}+1 / 2 \mathrm{M}$ (Fig. 2E-G).

These results indicated that TAC and MMF monotherapy or TAC combined with MMF at half the concentration exerted an inhibitory effect on mesangial cell proliferation in mice with LN, and the therapy regime of the combination of TAC and MMF at half the concentration was more effective than monotherapy in mice with $\mathrm{LN}$.

Combination of TAC and MMF inhibits the proliferation of mesangial cells in patients with LN. In total, 6 patients with biopsy-confirmed LN (classes IV) received combined treatment TAC and MMF and methyl prednisone for 6 months. The levels of the cell proliferation markers, Ki67 and PDGF, and the cell cycle-related protein, cyclin D1, were measured in the kidney biopsy samples of the patients by immunohistochemistry before and after 6 months of treatment. Following combination therapy for 6 months, the Ki67, PDGF and cyclin D1 levels were markedly decreased in the mesangial cells (Fig. 3).

Efficacy and safety of combination of TAC and MMF and methyl prednisone for the treatment of patients with LN. Changes in 24-h proteinuria, eGFR, albumin, SLEDAI, anti-dsDNA antibodies and C3 before and after treatment were compared to evaluate the efficacy and safety of the combination
A
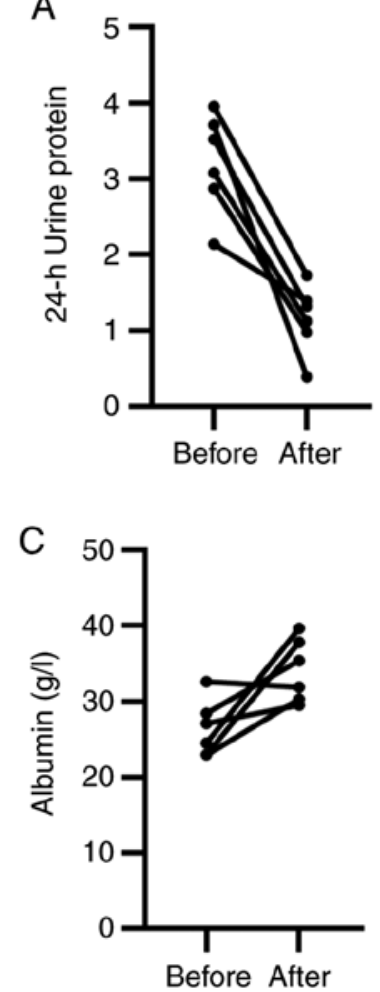
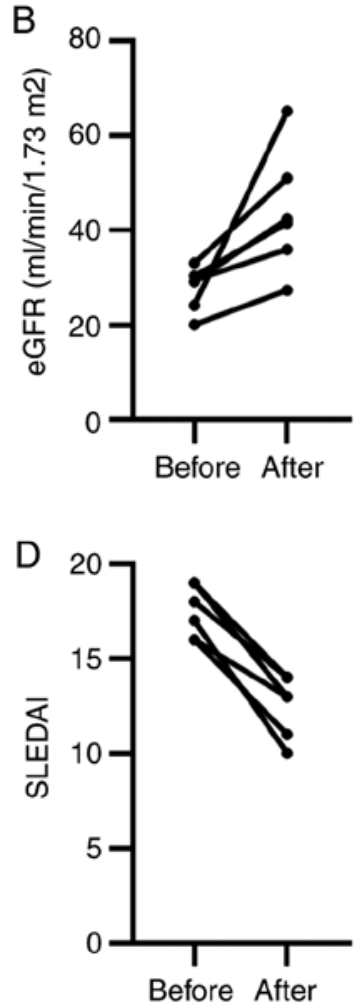

Figure 4. Clinical characteristics before and after combined tacrolimus, mycophenolate mofetil and methyl prednisone therapy of 6 patients with type IV lupus nephritis. Changes in (A) 24-h proteinuria, (B) eGFR, (C) albumin and (D) SLEDAI levels in the 6 patients before and after 6 months of treatment eGFR, estimated glomerular filtration rate.

of TAC, MMF and methyl prednisone in the treatment of LN. Following combination therapy for 6 months, the levels of 24-h proteinuria, eGFR, albumin and SLEDAI were significantly improved (Fig. 4). In 3 out of 5 patients, anti-dsDNA 
Table I. Changes in anti-dsDNA antibody and C3 levels in 6 patients before and after 6 months of treatment.

Before treatment

Patient no. Age (years) Disease history (months)

\begin{tabular}{|c|c|c|c|c|c|c|}
\hline 1 & 21 & 12 & + & + & - & - \\
\hline 2 & 26 & 3 & - & + & - & - \\
\hline 3 & 31 & 8 & + & + & + & + \\
\hline 4 & 24 & 4 & + & + & + & - \\
\hline 5 & 19 & 7 & + & + & - & + \\
\hline 6 & 36 & 15 & + & + & - & - \\
\hline
\end{tabular}

Table II. Adverse effects noted during the treatment period.

\begin{tabular}{|c|c|c|c|c|c|c|c|}
\hline Patient no. & Dyspepsia & $\begin{array}{l}\text { Transient abnormal } \\
\text { liver function }\end{array}$ & $\begin{array}{l}\text { Transient elevation of } \\
\text { serum creatinine }\end{array}$ & Leucopenia & $\begin{array}{c}\text { Severe } \\
\text { infection }\end{array}$ & Arrhythmia & $\begin{array}{l}\text { Menstrual } \\
\text { disorder }\end{array}$ \\
\hline 1 & + & - & - & - & - & - & + \\
\hline 2 & - & - & - & - & - & - & + \\
\hline 3 & - & + & - & - & - & - & - \\
\hline 4 & + & - & + & - & - & - & + \\
\hline 5 & - & - & - & - & - & - & - \\
\hline 6 & - & - & - & - & - & - & - \\
\hline
\end{tabular}

A

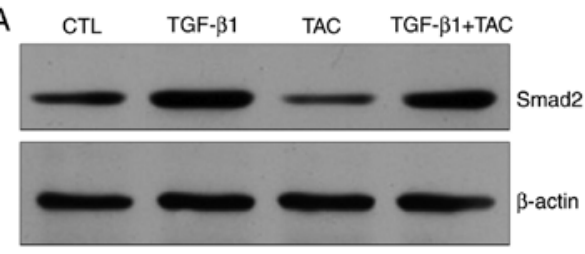

B

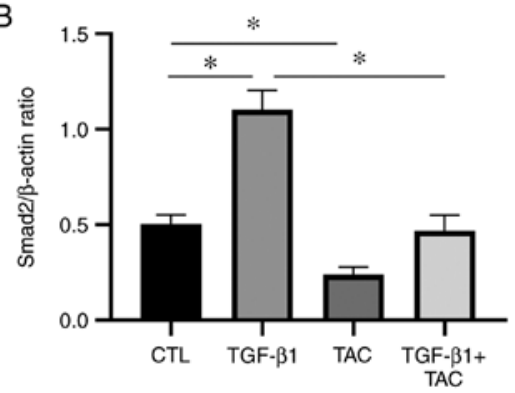

C

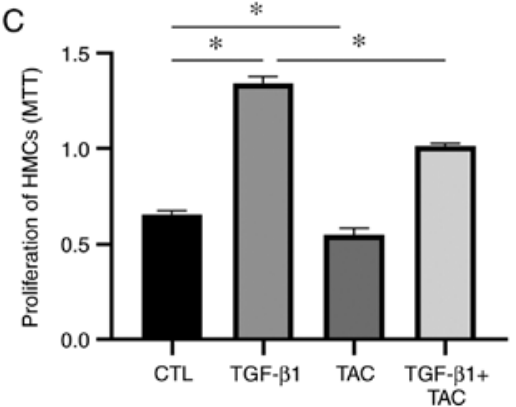

D CTL PDGF MMF PDGF+MMF

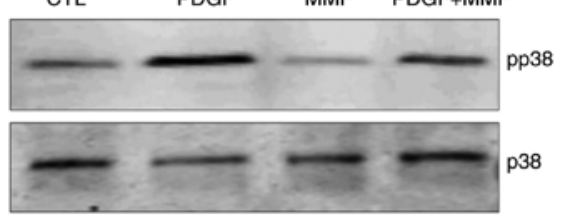

E

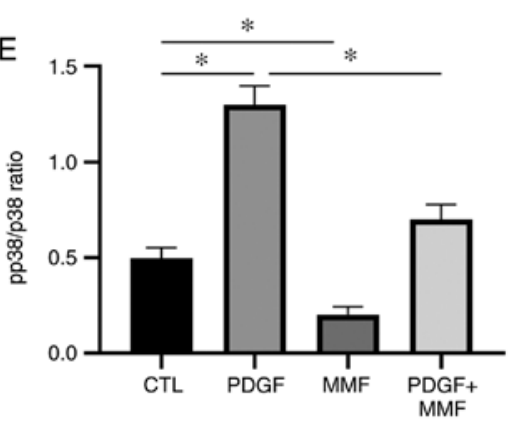

F

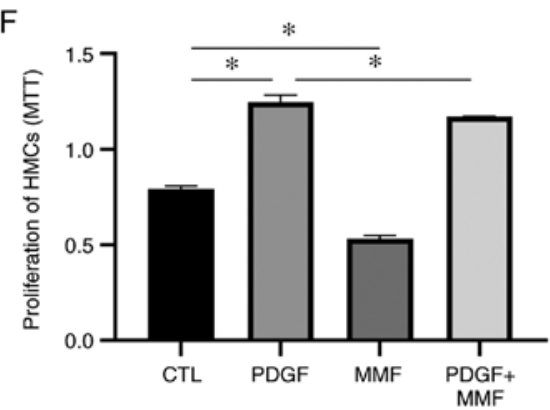

Figure 5. TAC and MMF inhibit HMC proliferation through different mechanisms. (A and B) A group of HMCs was cultured normally, while other groups of cells were treated with $5 \mathrm{ng} / \mathrm{ml} \mathrm{TGF}-\beta 1,5 \mu \mathrm{mol} / 1 \mathrm{TAC}$ or $5 \mathrm{ng} / \mathrm{ml}$ TGF- $\beta 1+5 \mu \mathrm{mol} / 1 \mathrm{TAC}$ for $48 \mathrm{~h}$. Western blot analysis was used to detect the expression of Smad2 ("P<0.01). (D and E) A group of HMCs was cultured normally, while other groups were treated with $20 \mathrm{ng} / \mathrm{ml} \mathrm{PDGF,} 10 \mu \mathrm{mol} / 1 \mathrm{MMF}$ or $20 \mathrm{ng} / \mathrm{ml} \mathrm{PDGF}+10 \mu \mathrm{mol} / 1 \mathrm{MMF}$ for $48 \mathrm{~h}$. The protein expression levels of phosphorylated $\mathrm{p} 38$ and pp38 were examined by western blot analysis ("P $<0.01$ ). (C and F) HMC proliferation was measured by MTT assay ("P<0.01). HMC, human mesangial cell; T or TAC, tacrolimus; M or MMF, mycophenolate mofetil. 


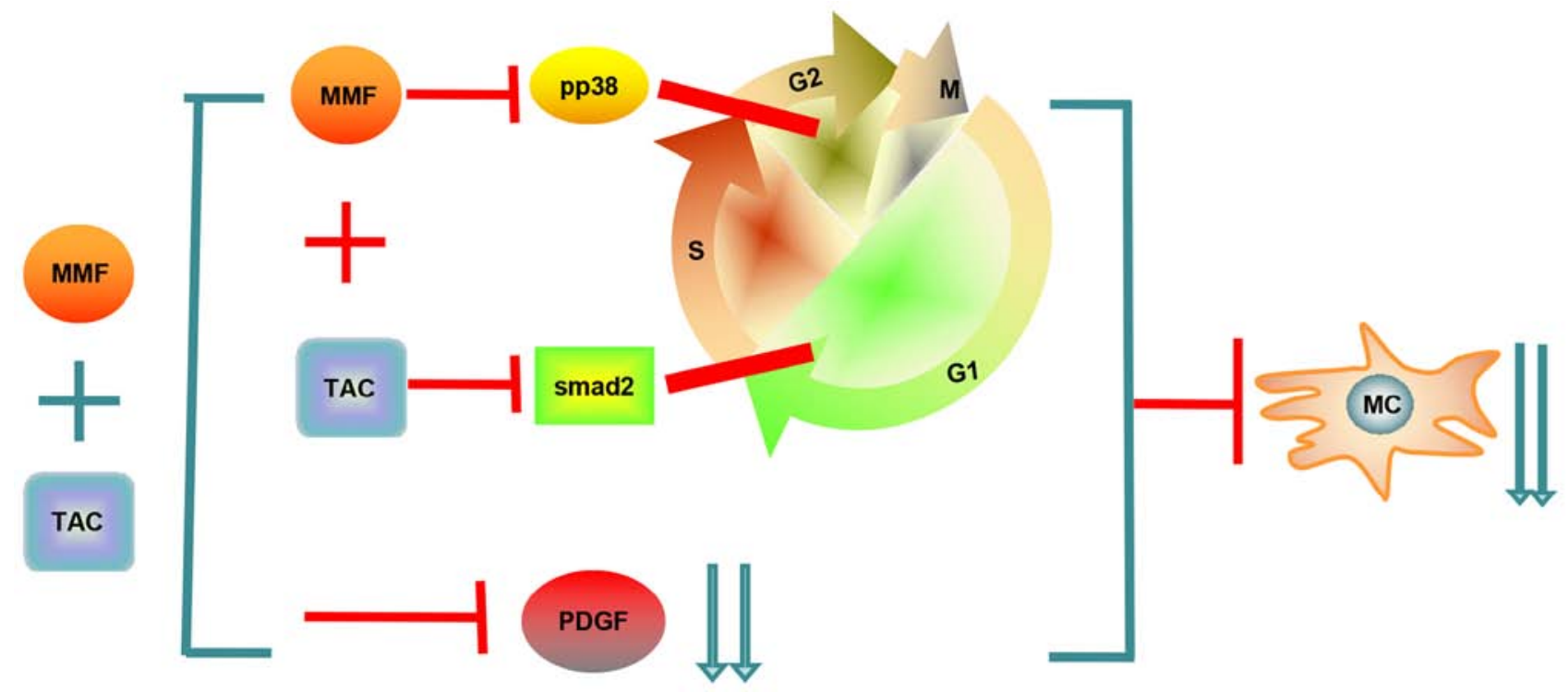

Figure 6. Tacrolimus and mycophenolate mofetil exert their inhibitory effect on mesangial cell proliferation by acting on different phases of the cell cycle of mesangial cells through different pathways.

antibody turned negative, and in 4 out of 6 patients, C3 levels were elevated (Table I). Some adverse effects occurred during the treatment period; however, none of these were considered serious (Table II).

TAC and MMF inhibit HMC proliferation through different mechanisms. To further investigate the mechanisms responsible for the inhibition of the proliferation of HMCs by TAC and MMF, TGF- $\beta 1$ and PDGF were used to stimulate the HMCs. A number of HMCs were cultured normally, while other HMCs were treated with $5 \mathrm{ng} / \mathrm{ml} \mathrm{TGF}-\beta 1,5 \mu \mathrm{mol} / 1 \mathrm{TAC}$ or $5 \mathrm{ng} / \mathrm{ml}$ $\mathrm{TGF}-\beta 1+5 \mu \mathrm{mol} / 1 \mathrm{TAC}$ for $48 \mathrm{~h}$. Western blot analysis was used to detect the expression of Smad2, and MTT assay was used to measure the cell proliferation rate. Detectable levels of Smad 2 were found in the control HMCs. TAC significantly decreased the level of Smad 2 and inhibited HMC proliferation compared with the control group. Incubation with TGF- $\beta 1$ induced an increase in Smad2 expression and HMC proliferation, which was significantly abrogated by TAC (Fig. 5A-C). These data demonstrated that TAC inhibited HMC proliferation by affecting the Smad2 signaling pathway (Fig. 6).

In addition, a group of HMCs was cultured normally, while other groups of cells were treated with $20 \mathrm{ng} / \mathrm{ml}$ PDGF, $10 \mu \mathrm{mol} / 1 \mathrm{MMF}$ or $20 \mathrm{ng} / \mathrm{ml} \mathrm{PDGF}+10 \mu \mathrm{mol} / 1 \mathrm{MMF}$ for $48 \mathrm{~h}$. The protein expression levels of p-p38 and p38 were examined by western blot analysis. Cell proliferation was measured by MTT assay. The results revealed that MMF decreased the level of p38 and inhibited HMC proliferation. PDGF induced the phosphorylation of p38 and HMC proliferation. However, following treatment with MMF, the opposite trend was observed (Fig. 5D-F). These data demonstrated that MMF inhibits HMC proliferation by affecting the p38 signaling pathway (Fig. 6).

\section{Discussion}

Glomerular mesangial cells have multiple functions, including the structural support of capillary clusters, regulation of glomerular hemodynamics and the phagocytic clearance of macromolecules and immune complexes $(17,18)$. In addition, they have a complex interaction with infiltrating inflammatory cells, and play an important role in the development of inflammation, fibrosis and glomerular sclerosis (19). The abnormal proliferation of mesangial cells is a common pathological change of proliferative glomerular disease (such as IgA nephropathy, nephrotic syndrome and LN). Under pathological conditions, mesangial cells proliferate in large quantities, release various inflammatory mediators and secrete extracellular matrix, which then causes glomerular sclerosis, fibrosis and ultimately leads to end-stage renal failure (20). Since the 1950s, hormones and immunosuppressants have found clinical applications. The multi-targeted use of immunosuppressants based on the cell cycle is a new direction in the treatment of kidney disease.

In a previous study, it was confirmed that TAC can block mesangial cells in the G0/G1 phase, preventing them from entering the $\mathrm{S}$ phase. MMF prevents mesangial cells in $\mathrm{S}$ phase from entering the $\mathrm{G} 2 / \mathrm{M}$ phase, thus inhibiting their proliferation (1). However, the effect of combining TAC and MMF based on cell cycle to inhibit the proliferation of mesangial cells, and whether it is more promiment than the effect of a single drug, remain unknown. In the present study, the inhibitory effect of TAC combined with MMF on mesangial cell proliferation was explored.

Three treatment regimens, TAC, MMF or $1 / 2 \mathrm{TAC}+$ $1 / 2 \mathrm{MMF}$, were applied to assess the proliferative stage of HMCs and mice with LN. The levels of antigen Ki67 and the cell cycle regulatory protein, cyclin D1, which reflect the proliferation of mesangial cells, were reduced following these treatments, and the changes indicated that all three treatment regimens inhibited mesangial cell proliferation. The expression of Ki67 and cyclin D1 in the $1 / 2 \mathrm{~T}+1 / 2 \mathrm{M}$ treatment group was lower than that in the other 2 treatment groups at the end of the experiment, and the differences were statistically significant. These results are consistent with the results of PAS 
and Masson's trichrome staining of mice with LN, indicating that the combination of TAC and MMF was more effective than monotherapy in vitro and in vivo. Furthermore, following the treatment of patients, biopsy-confirmed LN (classes IV) with combination TAC and MMF at half the dose, the levels of Ki67, PDGF and cyclin D1 were decreased significantly in the patient kidney samples. In addition, clinical indicators were also improved, and there were no severe adverse effects. These results confirmed that the combination of TAC and MMF at half the dose is an effective and safe regiment in the therapy of glomerular proliferative disease.

In fact, combination therapy with a steroid, TAC and MMF has achieved a good therapeutic effect in clinical practice in LN. Previous studies have found that the combination of TAC and MMF is more effective and safer than conventional treatment (intravenous cyclophosphamide and steroid) $(9,10,21,22)$. Some studies have reported that TAC combined with MMF treatment may be a beneficial option for patients with $\mathrm{LN}$ who exhibit an inadequate response to either cyclophosphamide or MMF treatment, or had lupus flares after achieving a complete response (23-25). However, whether the effect of TAC combined with MMF is better than single-drug treatment has not been reported to date. The present study compared the effect of combined TAC and MMF with single-drug therapy, and found that the combination therapy was more effective than monotherapy in vitro and in vivo. Additional clinical trials are required to verify this result.

The calcineurin inhibitor, TAC, is a macrolide immunosuppressant isolated from Streptomyces sinensis, TAC can combine with a protein in the cytoplasm (FKBP12) to form a complex, specifically bind to and inhibit calcineurin, inhibit the transmission of calcium-dependent signals generated by $\mathrm{T}$ cells, and prevent the activation of the $\mathrm{T}$ cell-specific transcription factor NF-AT, thereby inhibiting lymphocyte proliferation and lymphokine production (26). As an immunosuppressive agent, MMF is often used in the treatment of organ transplantation to prevent rejection and various immune diseases. Its active metabolite is mycophenolic acid, which is an inhibitor of IMPDH, a catalyst essential for the classical synthetic pathway of guanine nucleotides, which is essential for lymphocyte activation. Therefore, MMF inhibits the synthesis and proliferation of lymphocytes in the G1-S phase (27). Previous studies have demonstrated that the mechanisms through which combination therapy is more beneficial than single therapy are as follows: The additive suppression of T- and B-cell activation (28), anti-inflammatory and podocyte protection $(29,30)$. The present study uncovered novel synergistic mechanisms in TAC and MMF combination therapy for mesangial proliferative kidney disease.

PDGF is a platelet-derived mitogenic factor, and its proliferative effect on cells is mediated mainly by PDGF-BB. Previous in vivo and in vitro studies have indicated that PDGF-BB is the most important mitogenic factor that causes abnormal proliferation of mesangial cells, and plays a key role in the pathogenesis of glomerulonephritis. In addition, PDGF can stimulate the abnormal proliferation of HMCs (31). Thus, HMCs stimulated by PDGF were selected in the present study to establish a model of HMC hyperplasia. A previous study revealed that MMF decreased PDGF protein expression (32). In the present study, the expression of PDGF in mice with LN and in kidney tissues of patients with LN was detected by immunohistochemistry and western blot analysis. following TAC, MMF or $1 / 2 \mathrm{TAC}+1 / 2 \mathrm{MMF}$ treatment, the PDGF levels were decreased in mice with $\mathrm{LN}$ and in kidney tissues of patients with LN. Compared with that following treatment with TAC or MMF alone, the expression of PDGF following treatment with TAC combined with MMF at half the concentration was lower. These results demonstrated that both TAC and MMF reduced the expression of PDGF, and the combination of TAC and MMF exerted a synergistic effect in decreasing the expression of PDGF and inhibiting mesangial cell proliferation. This may be partially responsible for the inhibitory effect of TAC and MMF on mesangial cell proliferation.

TGF- $\beta 1$, as a multifunctional cytokine, plays an important role in regulating the physiological processes of cell growth, differentiation and biosynthesis (33). TGF- $\beta 1$ plays an important role in cell proliferation. After TGF- $\beta 1$ binds to the serine/threonine kinase receptor on the surface of mesangial cells, the signal is transferred from the cell membrane to the nucleus mediated by Smad proteins $(34,35)$. In the present study, TGF- $\beta 1$ was used to induce HMC proliferation. When the HMCs were treated with TGF- $\beta 1$, the expression of Smad2 protein was enhanced, which confirmed the existence of the Smad signaling pathway in mesangial cells. Treatment of the HMCs with TAC decreased the expression of Smad2 protein, which suggested that TAC inhibited the proliferation of mesangial cells at least in part by affecting the Smad signaling pathway.

Han et al reported the p38 signaling pathway for the first time (36). The p38 signaling pathway is one of the most important signaling pathway in cells. It plays an important role in multiple biological reactions, including cell cycle regulation, cell proliferation, development, differentiation, aging, apoptosis, immune response and tumorigenesis. Numerous drugs promote mesangial cell proliferation through the p38 signaling pathway $(37,38)$. When exposed to various stimuli, p38 is phosphorylated, p-p38 is transferred into the nucleus, further regulating downstream signaling molecules and the activity of transcription factors. In the present study, the phosphorylation rate of p38 increased significantly in PDGF-stimulated HMCs, which confirmed that the proliferation of HMCs involves the p38 signaling pathway. The ratio of p38 protein phosphorylation in HMCs stimulated by PDGF and treated with MMF was significantly lower than that in HMCs not treated with MMF, which suggested that MMF inhibited mesangial cell proliferation at least in part by affecting the p38 signaling pathway.

In conclusion, TAC and MMF exert their inhibitory effects on mesangial cell proliferation by acting on different phases of the cell cycle of mesangial cells through different pathways: TAC can block mesangial cells in the G0/G1 phase, preventing them from entering the $S$ phase via influencing the TGF- $\beta 1 /$ Smad signaling pathway; MMF prevents mesangial cells in the $\mathrm{S}$ phase from entering $\mathrm{G} 2 / \mathrm{M}$ phase via the $\mathrm{p} 38$ signaling pathway. Furthermore, the results confirmed that the combination of TAC and MMF therapy based on the cell cycle with half the concentration was more effective than monotherapy in inhibiting mesangial cell proliferation in vitro and in vivo. This synergistic effect on the inhibition of mesangial cell proliferation is mediated, at least in part, by a decrease in the expression of PDGF (Fig. 6). 
The combination of TAC and MMF at half the concentration can inhibit the proliferation of mesangial cells more effectively than TAC and MMF alone, suggesting that, according to the cell cycle, treatment of proliferative glomerular disease with multiple immunosuppressants agents can improve the therapeutic effect and reduce the dosage of immunosuppressive agents used in the treatment, thus reducing the occurrence of adverse reactions and providing a novel strategy for the treatment of mesangial proliferative disease. The findings suggest that, in the treatment of mesangial proliferative nephropathy, if the disease requires the combination of immunosuppressive agents, attention should be paid to the use of immunosuppressive agents acting at different sites and different phases of the cell cycle. These agents should be sequentially combined based on the cell cycle to avoid the simultaneous use of multiple immunosuppressive agents acting on the same site and at the same phase of the cell cycle. This can fully exert the therapeutic effect of immunosuppressants via different mechanisms, and can effectively avoid excessive inhibition of immunity, which may lead to adverse reactions. Additional clinical studies are warranted to assess the efficacy and safety of a multi-target therapy consisting of TAC, MMF and steroid compared with other therapies for glomerular proliferative disease.

\section{Acknowledgements}

The authors would like to thank Dr Xuewang Li of Peking Union Medical college Hospital for providing the human mesangial cells.

\section{Funding}

The present study was supported by the Province Natural Science Foundation of Shanxi (grant no. 201701D221263).

\section{Availability of data and materials}

All data generated or analyzed during this study are included in this published article or are available from the corresponding author on reasonable request.

\section{Authors' contributions}

YG performed the experiments and was a major contributor to the writing of the manuscript. HY performed the experiments. YW performed the histological examination of the kidneys. JT analyzed and interpreted the patient data. RL designed the study and reviewed the manuscript. XZ conceived and designed the study and performed the experiments. All authors read and approved the final manuscript.

\section{Ethics approval and consent to participate}

The Ethics Committee of Shanxi Provincial People's Hospital (Taiyuan, China) approved the study. Written informed consent was obtained from each patient or their legal representative, according to the Declaration of Helsinki. The animal experiments were performed according to protocols approved by the Institutional Animal Care and Use Committee of Shanxi Medical University.

\section{Patient consent for publication}

Not applicable.

\section{Competing interests}

The authors declare that they have no competing interests.

\section{References}

1. Pastukhov O, Schwalm S, Römer I, Zangemeister-Wittke U, Pfeilschifter $\mathrm{J}$ and Huwiler A: Ceramide kinase contributes to proliferation but not to prostaglandin E2 formation in renal mesangial cells and fibroblasts. Cell Physiol Biochem 34: 119-133, 2014.

2. Chhabra S, Liu Y, Hemmer MT, Costa L, Pidala JA, Couriel DR, Alousi AM, Majhail NS, Stuart RK, Kim D, et al: Comparative analysis of calcineurin inhibitor-based methotrexate and mycophenolate mofetil-containing regimens for prevention of graft-versus-host disease after reduced-intensity conditioning allogeneic transplantation. Biol Blood Marrow Transplant 25: 73-85, 2019.

3. Akool ES, Doller A, Babelova A, Tsalastra W, Moreth K, Schaefer L, Pfeilschifter J and Eberhardt W: Molecular mechanisms of TGFbeta receptor-triggered signaling cascades rapidly induced by the calcineurin inhibitors cyclosporin A and FK506. J Immunol 181: 2831-2845, 2008.

4. Huls G, Chitu DA, Havelange V, Jongen-Lavrencic M, van de Loosdrecht AA, Biemond BJ, Sinnige H, Hodossy B, Graux C, Kooy RVM, et al: Azacitidine maintenance after intensive chemotherapy improves DFS in older AML patients. Blood 133: 1457-1464, 2019.

5. Chang KH, Sanchez-Aguilera A, Shen S, Sengupta A, Madhu MN, Ficker AM, Dunn SK, Kuenzi AM, Arnett JL, Santho RA, et al: Vav3 collaborates with p190-BCR-ABL in lymphoid progenitor leukemogenesis, proliferation, and survival. Blood 120: 800-811, 2012.

6. Seo T, Fukushima T, Inoue H, Imamura S, Urasaki Y, Yoshida A, Kawai Y, Yamauchi T, Iwasaki H, Tsutani H, et al: Long-term follow-up of the clinical efficacy of chemotherapy for acute myeloid leukemia at a single institute. J Infect Chemother 7: 156-162, 2001.

7. Ekberg H, van Gelder T, Kaplan B and Bernasconi C: Relationship of tacrolimus exposure and mycophenolate mofetil dose with renal function after renal transplantation. Transplantation 92: 82-87, 2011.

8. Liu Z, Zhang H, Liu Z, Xing C, Fu P, Ni Z, Chen J, Lin H, Liu F, He Y, et al: Multitarget therapy for induction treatment of lupus nephritis: A randomized trial. Ann Intern Med 162: $18-26,2015$.

9. Zhang H, Liu Z, Zhou M, Liu Z, Chen J, Xing C, Lin H, Ni Z, Fu P, Liu F, et al: Multitarget therapy for maintenance treatment of lupus nephritis. J Am Soc Nephrol 28: 3671-3678, 2017.

10. Bao H, Liu ZH, Xie HL, Hu WX, Zhang HT and Li LS: Successful treatment of class V+IV lupus nephritis with multitarget therapy. J Am Soc Nephrol 19: 2001-2010, 2008.

11. Zhou X, Workeneh B, Hu Z and Li R: Effect of immunosuppression on the human mesangial cell cycle. Mol Med Rep 11: 910-916, 2015.

12. Delarue F, Virone A, Hagege J, Lacave R, Peraldi MN, Adida C, Rondeau E, Feunteun J and Sraer JD: Stable cell line of T-SV40 immortalized human glomerular visceral epithelial cells. Kidney Int 40: 906-912, 1991.

13. Hochberg MC: Updating the American college of rheumatology revised criteria for the classification of systemic lupus erythematosus. Arthritis Rheum 40: 1725, 1997.

14. Penault-Llorca F and Radosevic-Robin N: Ki67 assessment in breast cancer: An update. Pathology 49: 166-171, 2017.

15. Casimiro MC, Velasco-Velázquez M, Aguirre-Alvarado C and Pestell RG: Overview of cyclins D1 function incancer and the CDK inhibitorlandscape past and present. Expert Opin Investig Drugs 23: 295-304, 2014.

16. Mai S, Zou L, Tian X, Liao X, Luan Y, Han X, Wei Y, Wu Y, Kuang S, Yang Y, et al: Double-edged effect of hydroxychloroquine on human umbilical cord-derived mesenchymal stem cells treating lupus nephritis in MRL/lpr Mice. Mol Pharm 15: 1800-1813, 2018. 
17. Johnson RJ, Floege J, Yoshimura A, Iida H, Couser WG and Alpers CE: The activated mesangial cell: A glomerular 'myofibroblast'? J Am Soc Nephrol 2 (10 Suppl): S190-S197, 1992.

18. Alhassona F, Setha RK, Sarkara S, Kimonoa DA, Albadrania MS, Dattaroya D, Chandrashekarana V, Scotta GI, Raychoudhuryb S, Nagarkattic M, et al: High circulatory leptin mediated NOX-2-peroxynitrite-miR 21 axis activate mesangial cells and promotes renal inflammatory pathology in nonalcoholic fatty liver disease. Redox Biol 17: 1-15, 2018.

19. Pereira RL, Felizardo RJ, Cenedeze MA, Hiyane MI, Bassi EJ, Amano MT, Origassa CS, Silva RC, Aguiar CF, Carneiro SM, et al: Balance between the two kinin receptors in the progression of experimental focal and segmental glomerulosclerosis in mice. Dis Model Mech 7: 701-710, 2014.

20. Scindia YM, Deshmukh US and Bagavant H: Mesangial pathology in glomerular disease: Targets for therapeutic intervention. Adv Drug Deliv Rev 62: 1337-1343, 2010.

21. Deng J, Luo L, Zhu L, Xie H and Xie H: Multitarget therapy versus intravenous cyclophosphamide in the induction treatment oflupus nephritis: A metaanalysis of randomized controlled trials. Turk J Med Sci 48: 901-910, 2018.

22. Zhou T, Lin S, Yang S and Lin W: Efficacy and safety of tacrolimus in induction therapy of patients with lupus nephritis. Drug Des Devel Ther 13: 857-869, 2019.

23. Park DJ, Kang JH, Lee KE, Bae SC, Chung WT, Choe JY, Jung SY, Kim YS, Lee HS, Lee J, et al: Efficacy and safety of mycophenolate mofetil and tacrolimus combination therapy in patients with lupus nephritis a nationwide multicentre study. Clin Exp Rheumatol 37: 89-96, 2019.

24. Mok CC, To CH, Yu KL and Ho LY: Combined low-dose mycophenolate mofetil and tacrolimus for lupus nephritis with suboptimal response to standard therapy: A 12-month prospective study. Lupus 22: 1135-1141, 2013.

25. Choi CB, Won S and Bae SC: Outcomes of multitarget therapy using mycophenolate mofetiland tacrolimus for refractory or relapsing lupus nephritis. Lupus 27: 1007-1011, 2018.

26. Prytuła A and van Gelder T: Clinical aspects of tacrolimus use in paediatric renal transplant recipients. Pediatr Nephrol 34: 31-43, 2019.

27. Dubus I, Vendrely B, Christophe I, Labouyrie JP, Delmas Y, Bonnet $\mathbf{J}$ and Combe $\mathrm{C}$ : Mycophenolic acid antagonizes the activation of cultured human mesangial cells. Kidney Int 62: 857-867, 2002
28. Wiseman AC: Immunosuppressive medications. Clin J Am Soc Nephrol 11: 332-343, 2016.

29. Fu J, Wang Z, Lee K, Wei C, Liu Z, Zhang M, Zhou1 M, Cai M, Zhang W, Chuang PY, et al: Transcriptomic analysis uncovers novel synergistic mechanisms in combination therapy for lupus nephritis. Kidney Int 93: 416-429, 2018.

30. Manabe S, Nitta K and Nagata M: Direct effects of immunomodulatory agents on podocytes in immune-mediated glomerular diseases. Contrib Nephrol 195: 131-142, 2018.

31. Shultz PJ, DiCorleto PE, Silver BJ and Abboud HE: Mesangial cells express PDGF $m R N A s$ and proliferate in response to PDGF. Am J Physiol 255 (4 Pt 2): F674-F684, 1988.

32. Sabuda-Widemann D, Grabensee B, Schwandt C and Blume C: Mycophenolic acid inhibits the autocrine PDGF-B synthesis and PDGF-BB-induced mRNA expression of Egr-1 in rat mesangial cells. Nephrol Dial Transplant 24: 52-61, 2009.

33. Liu HF, Liu H, Lv LL, Ma KL, Wen Y, Chen L and Liu BC: CCN3 suppresses TGF-b1-induced extracellular matrix accumulation in human mesangial cells in vitro. Acta Pharmacol Sin 39: 222-229, 2018

34. Yoon J, Lee YJ, Namgung S, Han BH, Choi ES, Kang DG and Lee HS: Samchuleum attenuates diabetic renal injury through the regulation of TGF- $\beta /$ Smad signaling in human renal mesangial cells. Mol Med Rep 17: 3099-3108, 2018

35. Zhang L, Han C, Ye F, He Y, Jin Y, Wang T, Wu Y, Jiang Y, Zhang $\mathrm{F}$ and Jin $\mathrm{X}$ : Plasma gelsolin induced glomerular fibrosis via the TGF- $\beta 1 /$ Smads signal transduction pathway in $\operatorname{Ig} \mathrm{A}$ nephropathy. Int J Mol Sci 18: 390, 2017.

36. Han J, Lee JD, Bibbs L and Ulevitch RJ: A MAP kinase targeted by endotoxin and hyperosmolarity in mammalian cells. Science 265: 808-811, 1994

37. Li X, Wang L and Ma H: Betaine alleviates high glucose-induced mesangial cell proliferation by inhibiting cell proliferation and extracellular matrix deposition via the AKT/ERK1/2/p38 MAPK pathway. Mol Med Rep 20: 1754-1760, 2019.

38. Kim D, Li HY, Lee JH, Oh YS and Jun HS: Lysophosphatidic acid increases mesangial cell proliferation in models of diabetic nephropathy via Rac1/MAPK/KLF5 signaling. Exp Mol Med 51: 1-10, 2019.

\footnotetext{
This work is licensed under a Creative Commons Attribution-NonCommercial-NoDerivatives 4.0 International (CC BY-NC-ND 4.0) License.
} 